\title{
The effect of adequate alcohol intake on the efficiency of second language learning
}

\author{
Junyong Park ${ }^{1 \#}$, Seong Gak Jeon ${ }^{1 \#}$, Anton Joseph Mapoy ${ }^{2}$, Matthew Louis Grandmason ${ }^{2}$, Devin Paul Nowroski², Kiril Peev², DJ Dykes ${ }^{2}$, Peng \\ Ting $^{2}$, Tamara Taylor ${ }^{2}$, Michael C Shore ${ }^{3}$, Young Soon Seo ${ }^{3}$, Ji Hyeon Yun ${ }^{2}$, Yuri Bae ${ }^{2}$, Youngho Moon ${ }^{2}$ and Minho Moon ${ }^{1 *}$ \\ ${ }^{1}$ Department of Biochemistry, College of Medicine, Konyang University, Daejeon 35365, Republic of Korea \\ ${ }^{2}$ YC College, Pusan 48434, Republic of Korea \\ ${ }^{3}$ Kyungsung University, Pusan 48434, Republic of Korea \\ "Both authors contributed equally to this work.
}

\begin{abstract}
Side effects from acute and chronic alcohol consumption are well known. Paradoxically, however, the possibility that a moderate intake of alcohol may have a positive impact on secondary language learning has long been reported, and is also a popular belief. Recently, it has been reported that alcohol consumption improves the pronunciation of foreign languages as well as the memory effect. However, there is no definitive report on the mechanism by which alcohol is involved in memory enhancement and language learning. This review aims to provide an understanding of these effects and provide a blueprint for futher research by neurologically describing the mechanisms and possibilities that alcohol may have on language learning.
\end{abstract}

\section{Introduction}

Research on the behavioral effects of alcohol tends to focus on impairments of function and performance, and much evidence suggests that alcohol causes dysfunction on many levels. For example, Jellinek and McFarland found that alcohol induces moderate impairment of short-term memory [1], and Kalin et al. report that "people drink for thinking, talking or acting in an uncoordinated, inefficient way." [2].

In contrast, Vogel found that performance of any task can improve with a low blood alcohol concentration [3]. Gaines reported that moderate amounts of alcohol improved abstract thinking, likely due to anxiety reduction. It has been reported that small amounts of alcohol may initially improve associative memory formation and logical reasoning, which then subsequently decline with further alcohol consumption [4]. Guiora concluded that small amounts of alcohol (approximately one and a half ounces) increase the permeability of ego boundaries and increase empathic capacity, resulting in the nativelike pronunciation of a second language [5]. In a recent study of 50 German native speakers who learned Dutch, a group of low-alcoholic drinkers was rated by Dutch native observers to be significantly better at pronouncing than a group of beverages drinkers [6]. In addition, in the environment where participants drink alcohol ad libitum at home, the unit of alcohol drunk and the facilitation of memory retrograde showed a positive correlation [7]. This paper will review several studies that show contrasting effects of alcohol on the human body, and will examine the effects of alcohol on pronunciation of a second language and learning.

\section{Background}

\section{Mechanism of action of alcohol}

Alcohol consumption suppresses neural activity and results in attention deficits, alterations in memory, mood changes, drowsiness, and other behavioral alterations [8]. Alcohol-induced brain dysfunction is characterized in several ways. For example, visual and auditory memories are well maintained if visual and auditory cues are presented at the same time. However, memory deficits are observed if visual and auditory cues are presented in sequence. This suggests that alcohol disrupts memory storage, rather than working memory capacity [9]. This effect of alcohol results from activation of inhibitory neurotransmitters such as GABA or glycine, in the mesolimbic dopamine (DA) system [10], and excitatory neurotransmitters such as glutamate [11], N-methyl-D-aspartate (NMDA) and non-NMDA receptors [12]. According to a study that compared glucose utilize in alcohol-preferring rats ( $\mathrm{P}$ rats) and alcohol non-preferring rats (NP rats), glucose increased in the prefrontal cortex (PFC), and did not increase in the basal ganglia or the corpus callosum [13]. Furthermore, $P$ rats showed higher utilization of glucose in the PFC while in a drug naïve state compared to NP rats [14]. In the case of $\mathrm{P}$ rats, $\mathrm{PFC}$ glucose utilize increased at lower alcohol concentrations, and decreased and decreased at higher concentrations. Alcohol NP rats showed no difference in glucose utilize based on alcohol concentration [15]. This suggests that enhanced sensitivity to alcohol in the PFC is important for the development of alcohol dependence.

\section{Lowered inhibition}

The tongue loosening effect of alcohol may be due to reduced concern regarding mistakes in grammar [16] or to increased permeability of

Correspondence to: Minho Moon, Department of Biochemistry, College of Medicine, Konyang University, Korea, Tel: +82-42-600-6456; E-mail: hominmoon@konyang.ac.kr

Key words: alcohol, ethanol, language, learning, memory

Received: September 20, 2017; Accepted: November 06, 2017; Published: November 09, 2017 
ego boundaries [5]. The PFC is functionally and structurally adaptable by past experience. Normally, the PFC has inhibitory control over internal and external sensory-driven compulsive behaviors based on information obtained from past experiences. Continuous exposure to alcohol weakens PFC behavioral inhibition due to reward signals from the ventral tegmental area (VTA) dopaminergic system [17]. Furthermore, alcohol-induced reduction in social inhibition is due to the inhibition of inhibitory neurotransmitters [18]

In second language learning, pronunciation has unique characteristics that integrate the various functions of the ego used when learning grammar, syntax, and vocabulary [5]. Alcohol inhibits neural activity in the hippocampus, a brain region associated with memory, resulting in learning and memory impairment [8]. It is thought that these deficits occur due to increased grammatical and pronunciation errors. However, some anxiety also promotes language acquisition [19]. Thus, we can conclude that alcohol should be consumed in small amounts.

In contrast to alcohol, the sedative drug valium did not affect performance on a pronunciation test or lower inhibition [19]. Subjects under deep hypnosis perform better on learning tasks than those under lesser types of hypnosis [20]. Therefore, there are other potential mechanisms that regulate lowered inhibition.

\section{Learning mechanisms}

The PFC is the apex of the perception-action cycle that organizes purposeful goal-directed action and higher order behaviors such as language reasoning [21]. The orbitofrontal cortex (OFC) that extensively connected to the region of the limbic system are regulates cognitive needs such as memory and an "executive" network in the dorsolateral PFC (medial PFC in rodents). The interaction of these two areas plays an important role in determining behavioral responses [22,23]. This sequential processing of attention, planning, and decision making is referred to as "working memory" for the near past and "attentional set" the for near future. The inhibitory control of inappropriate behaviors of the dorsolateral PFC is important in the determination of behavior [17]. Examples include alcohol-induced incorrect memory of a sequence of audiovisual stimuli [9] and motivation related to addiction [24]. An in vitro study compared depolarization of membrane potential (up-state) caused by two weeks of persistent electrical stimulation of the VTA after triple-slice organotypic culture of PFC neurons while in an alcohol bath, to induce conditions similar to the in vivo bursting observed in the VTA in response to reward stimuli. It was found that the latter had less alcohol-induced inhibition, which was blocked after treatment with a DA1 receptor antagonist [25]. This suggests that the inhibitory action of alcohol on DA neuron bursting is offset and is related to enhanced NMDA receptor activity. In addition, treatment of cultured PFC neurons with a low concentration of an NMDA antagonist showed reduced the duration, amplitude, and spiking of the up-state [25]. Thus, it was determined that alcohol targets NMDA receptors located on PFC pyramidal neurons to regulate their function and inhibit persistent activity. Furthermore, in the presence of alcohol, cultured PFC pyramidal cells and fast-spiking GABA interneurons were activated simultaneously by electrical stimulation, despite the differences in electrical activity states [26]. These results show that highly interconnected recurrent networks exist between excitatory and inhibitory neurons in the PFC. Several studies have shown that alcohol changes glutamatergic neurotransmission in projections from the PFC and causes neuroplasticity in associative learning [10,17,27].

Therefore, alcohol acts on PFC neurons through NMDA receptor inhibition resulting in changes in glutamatergic signaling through interconnected networks, interferes with the inhibitory control of the PFC and induces neuroplasticity.

\section{Long-term potentiation}

Long-term potentiation (LTP) refers to a sudden, but long-term increase in the overall level of excitatory neurotransmission in the hippocampus, and is required for memory formation [28,29]. LTP requires glutamate receptor activation, along with $\mathrm{GABA}_{\mathrm{A}}$ receptor $\left(G_{A B} A_{A} R\right)$ inhibition. However, alcohol inhibits glutamate and excites $\mathrm{GABA}_{\mathrm{A}} \mathrm{R}$, ultimately inhibiting LTP $[30,31]$.

\section{Plasticity}

Imaging PFC activity using transcranial magnetic stimulation (TMS) shows that the harmful effects of alcohol are attributed to the breakdown of functional specificity in different brain regions [32]. A decrease in functional heterogeneity in the right prefrontal cortex was observed after alcohol consumption [32]. Decreased performance on a verbal fluency task in intoxicated participants was observed to correspond to lateral activation of the left dorsolateral PFC, the area associated with language [33]. Another study examined the effect of acute alcohol on memory encoding, which has also been associated with the right PFC [34]. In all experiments, alcohol lowered task performance and was associated with decreased bilateral PFC activity.

\section{Reversibility}

As described above, previous studies have demonstrated that alcohol dependent patients showed a decrease in glucose metabolism in the medial frontal cortex and poor performance on the Wisconsin Card Sorting Task [35]. After 16-30 days of abstinence, frontal glucose metabolism increased, suggesting that behavioral consequences of chronic alcoholics is reversible [36]. In addition, abstinent participants showed an increase in cognitive and executive function with corresponding increases in frontal glucose metabolism [37].

\section{Conclusion}

This paper suggest that the effects of alcohol on fluency and language learning ability are due to inhibition of inhibitory control of the PFC, specifically, by inhibiting glutamatergic NMDA receptors in PFC neurons and interconnected networks. Additionally, although alcohol has positive effects on fluency, it has negative effects on learning by reducing the inhibition of inappropriate learning. Further, alcohol induces plasticity in PFC neurons, which is necessary for learning. To prevent learning deficits, alcohol should be consumed in small doses and not for prolonged periods of time (Figure 1).

Future studies should investigate the interaction of neuronal activity and the mechanism of action of alcohol. Additionally, future studies should examine the mechanism by which fluency becomes possible. Understanding the relationship between fluency and anxiety will be helpful for language therapy.

To investigate physiological and structural changes in the PFC in response to varying alcohol concentrations, the following techniques will need to be used: micromolecular techniques, functioning brain imaging studies, use of animal models, and coordinated study of neuroscience, neurophysiology, psychiatry, and psychology. Additionally, research should be directed to determine ways other than involving the use of alcohol to enable hypnosis and fluency.

\section{Acknowledgement}

This work was supported by Basic Science Research Program through the National Research Foundation of Korea (NRF) funded by the Ministry of Science, ICT \& Future Planning (NRF2015R1C1A1A01052732). 


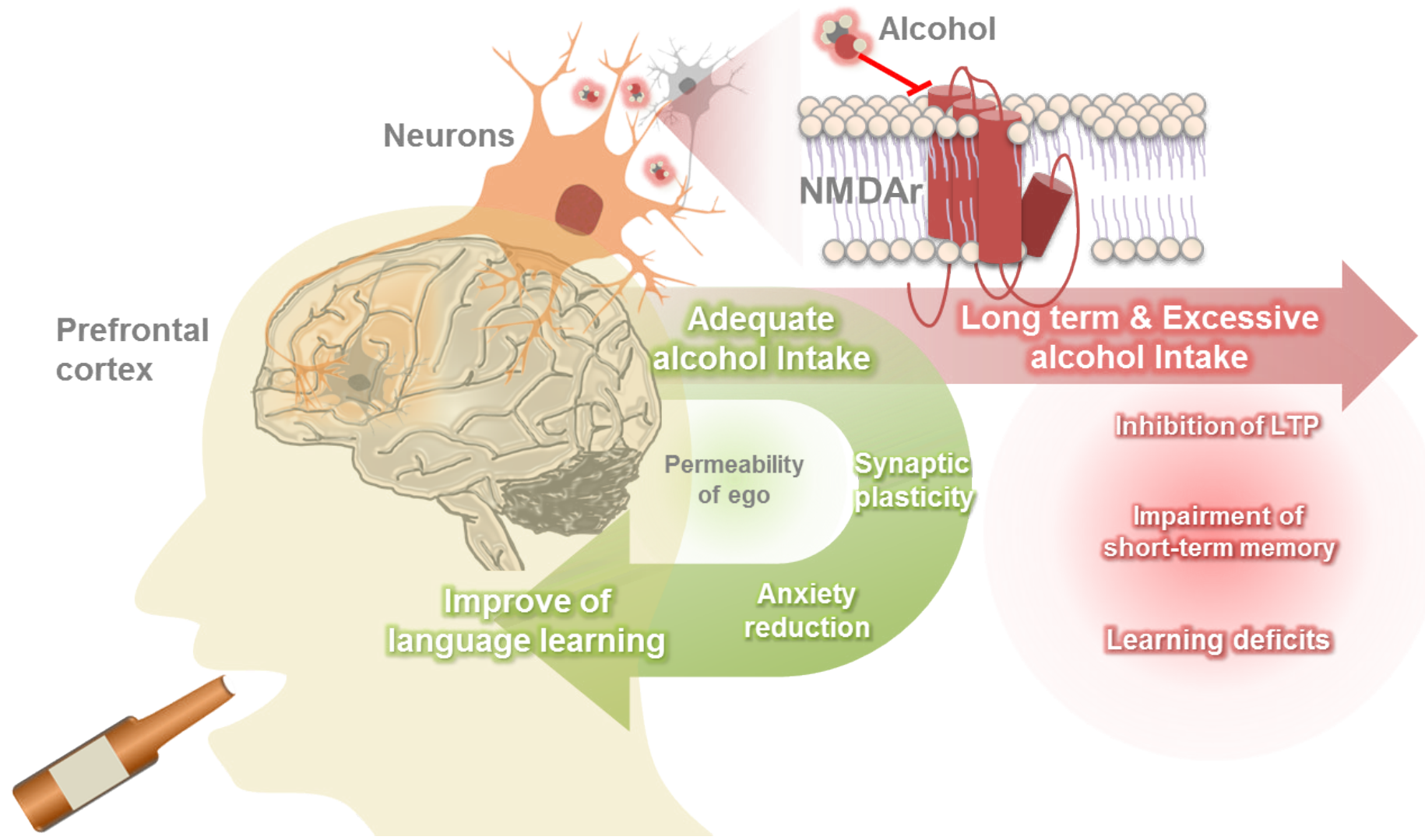

Figure 1. Schematic drawing of the language learning efficiency according to alcohol consumption.

\section{References}

1. Jellinek EM, McFarland RA (1940) Analysis of psychological experiments on the effects of alcohol. Q J Stud Alcohol 1: 272-371.

2. Kalin R, Mcclelland DC, Kahn M (1965) The effects of male social drinking on fantasy. J Pers Soc Psychol 1: 441-452. [Crossref]

3. Vogel M (1958) Low blood alcohol concentrations and psychological adjustment as factors in psychomotor performance: an exploratory study. Q J Stud Alcohol 19: 573589.

4. Gaines J (1960) The temporary effects of varying amounts of alcohol on abstract thinking efficiency. Dissertat Abstract 20: 2918.

5. Guiora AZ, Beit-Hallahmi B, Brannon RC, Dull CY, Scovel T (1972) The effects of experimentally induced changes in ego states on pronunciation ability in a second language: an exploratory study. Compr Psychiatry 13: 421-428. [Crossref]

6. Renner F, Kersbergen I, Field M, Werthmann J (2017) Dutch courage? Effects of acute alcohol consumption on self-ratings and observer ratings of foreign language skills. $J$ Psychopharmacol. [Crossref]

7. Carlyle M, Dumay N, Roberts K, McAndrew A, Stevens T, et al. (2017) Improved memory for information learnt before alcohol use in social drinkers tested in a naturalistic setting. Sci Rep 7: 6213. [Crossref]

8. White AM, Matthews DB, Best PJ (2000) Ethanol, memory, and hippocampal function: a review of recent findings. Hippocampus 10: 88-93. [Crossref]

9. Saults JS, Cowan N, Sher KJ, Moreno MV (2007) Differential effects of alcohol on working memory: distinguishing multiple processes. Exp Clin Psychopharmacol 15: 576-587. [Crossref]

10. Leriche M, Mendez M, Zimmer L, Berod A (2008) Acute ethanol induces Fos in GABAergic and non-GABAergic forebrain neurons: a double-labeling study in the medial prefrontal cortex and extended amygdala. Neurosci 153: 259-267. [Crossref]

11. Pascual M, Boix J, Felipo V, Guerri C (2009) Repeated alcohol administration during adolescence causes changes in the mesolimbic dopaminergic and glutamatergic systems and promotes alcohol intake in the adult rat. $J$ Neurochem 108: 920-931. [Crossref]
12. Weitlauf C, Woodward JJ (2008) Ethanol selectively attenuates NMDAR-mediated synaptic transmission in the prefrontal cortex. Alcohol Clin Exp Res 32: 690-698. [Crossref]

13. Volkow ND, Hitzemann R, Wolf AP, Logan J, Fowler JS, et al. (1990) Acute effects of ethanol on regional brain glucose metabolism and transport. Psychiatry Res 35: 39-48. [Crossref]

14. Smith DG, Learn JE, McBride WJ, Lumeng L, Li TK, et al. (2001) Alcohol-naive alcohol-preferring $(\mathrm{P})$ rats exhibit higher local cerebral glucose utilization than alcoholnonpreferring (NP) and Wistar rats. Alcohol Clin Exp Res 25: 1309-1316. [Crossref]

15. Strother WN, McBride WJ, Lumeng L, Li TK (2005) Effects of acute administration of ethanol on cerebral glucose utilization in adult alcohol-preferring and alcoholnonpreferring rats. Alcohol 35: 119-128. [Crossref]

16. Sayette MA (1993) An appraisal-disruption model of alcohol's effects on stress responses in social drinkers. Psychol Bull 114: 459-476. [Crossref]

17. Abernathy K, Chandler LJ, Woodward JJ (2010) Alcohol and the prefrontal cortex. Int Rev Neurobiol 91: 289-320. [Crossref]

18. Valenzuela CF (1997) Alcohol and neurotransmitter interactions. Alcohol Health Res World 21: 144-148. [Crossref]

19. Guiora AZ, Acton WR, Erard R, Strickland FW (1980) The effects of benzodiazepine (valium) on permeability of language ego boundaries 1. Language Learning 30: 351361.

20. Schumann JH, Holroyd J, Campbell RN, Ward FA (1978) Improvement of foreign language pronunciation under hypnosis: a preliminary study. Language Learning 28 : 143-148.

21. Arbib MA (1985) Schemas for the temporal organization of behaviour. Hum Neurobiol 4: 63-72. [Crossref]

22. Bush G, Luu P, Posner MI (2000) Cognitive and emotional influences in anterior cingulate cortex. Trends Cogn Sci 4: 215-222. [Crossref]

23. Barbas H (1995) Anatomic basis of cognitive-emotional interactions in the primate prefrontal cortex. Neurosci Biobehav Rev 19: 499-510. [Crossref] 
24. Gladwin TE, Figner B, Crone EA, Wiers RW (2011) Addiction, adolescence, and the integration of control and motivation. Dev Cogn Neurosci 1: 364-376. [Crossref]

25. Tu Y, Kroener S, Abernathy K, Lapish C, Seamans J, et al. (2007) Ethanol inhibits persistent activity in prefrontal cortical neurons. J Neurosci 27: 4765-4775. [Crossref]

26. Woodward JJ, Pava MJ (2009) Effects of ethanol on persistent activity and up-States in excitatory and inhibitory neurons in prefrontal cortex. Alcohol Clin Exp Res 33: 2134-2140. [Crossref]

27. Berke JD, Hyman SE (2000) Addiction, dopamine, and the molecular mechanisms of memory. Neuron 25: 515-532. [Crossref]

28. Bliss TV, Collingridge GL (1993) A synaptic model of memory: long-term potentiation in the hippocampus. Nature 361: 31-39. [Crossref]

29. Whitlock JR, Heynen AJ, Shuler MG, Bear MF (2006) Learning induces long-term potentiation in the hippocampus. Science 313: 1093-1097. [Crossref]

30. Möykkynen T, Korpi ER (2012) Acute effects of ethanol on glutamate receptors. Basic Clin Pharmacol Toxicol 111: 4-13. [Crossref]

31. Schummers J, Browning MD (2001) Evidence for a role for GABA(A) and NMDA receptors in ethanol inhibition of long-term potentiation. Brain Res Mol Brain Res 94: 9-14. [Crossref]
32. Kahkonen S, Wilenius J, Nikulin VV, Ollikainen M, Ilmoniemi RJ (2003) Alcohol reduces prefrontal cortical excitability in humans: a combined TMS and EEG study. Neuropsychopharmacology 28: 747-754. [Crossref]

33. Wendt PE, Risberg J (2001) Ethanol reduces rCFB activation of left dorsolateral prefrontal cortex during a verbal fluency task. Brain Lang 77: 197-215. [Crossref]

34. Söderlund H, Grady CL, Easdon C, Tulving E (2007) Acute effects of alcohol on neural correlates of episodic memory encoding. Neuroimage 35: 928-939. [Crossref]

35. Adams KM, Gilman S, Koeppe RA, Kluin KJ, Brunberg JA, et al. (1993) Neuropsychological deficits are correlated with frontal hypometabolism in positron emission tomography studies of older alcoholic patients. Alcohol Clin Exp Res 17: 205210. [Crossref]

36. Volkow ND, Wang GJ, Hitzemann R, Fowler JS, Overall JE, et al. (1994) Recovery of brain glucose metabolism in detoxified alcoholics. Am J Psychiatry 151: 178-183. [Crossref]

37. Johnson-Greene D, Adams KM, Gilman S, Koeppe RA, Junck L, et al. (1997) Effects of abstinence and relapse upon neuropsychological function and cerebral glucose metabolism in severe chronic alcoholism. J Clin Exp Neuropsychol 19: 378-385. [Crossref]

Copyright: (C2017 Park J. This is an open-access article distributed under the terms of the Creative Commons Attribution License, which permits unrestricted use, distribution, and reproduction in any medium, provided the original author and source are credited. 